\title{
Use of ulipristal acetate, levonorgestrel and the copper- intrauterine device for emergency contraception following the introduction of new FSRH guidelines
}

\author{
Aisling Susan Baird
}

Consultant in Sexual and Reproductive Healthcare, Liverpool Community Health, Central Abacus, Liverpool, UK

\section{Correspondence to}

Dr Aisling Susan Baird, Liverpool Community Health, Central Abacus, Citrus House, 40-46 Dale Street Liverpool L2 5SF, UK. aisling.baird@liverpoolch.nhs.uk

Received 26 August 2012 Revised 12 January 2013 Accepted 29 January 2013 Published Online First 25 April 2013
To cite: Baird AS. J Fam Plann Reprod Health Care 2013;39:264-269.

\begin{abstract}
Objectives The UK Faculty of Sexual \& Reproductive Healthcare (FSRH) has recommended that for emergency contraception (EC) the health professional should discuss individual needs and inform women of the different methods, efficacy, adverse effects, interactions, eligibility and additional contraception. In our sexual and reproductive health care service (Liverpool and Knowsley, UK), revised guidance was issued in early 2012, reflecting Faculty advice. We studied (1) how our use of EC changed, (2) which methods were offered and how this changed, (3) which method was chosen by women who were offered all three UK licensed methods of EC and (4) the appropriateness of the offer of only levonorgestrel (LNG).
\end{abstract}

Methods We studied a total of 2989 case records in the 3 months before and 3 months following the adoption by our service of the 2011 FSRH guidance. This was a retrospective review of charts undertaken by interrogating our computerised Excelicare ${ }^{\circledR}$ system of clinical records. All EC episodes in the two 3-month periods were analysed, covering OctoberDecember 2011 and March-May 2012.

Additionally, three non-probabilistic, purposeful samples of representative practitioners' charts were examined in groups of women offered all methods [and choosing either ulipristal acetate (UPA) or LNG] or who were offered LNG only. Results The use of LNG fell from $93.0 \%$ of EC issued to $76.0 \%$; UPA use rose from $3.0 \%$ to $18.7 \%$. In the second 3-month period, of the women offered all three methods, $54.9 \%$ chose LNG and 39.8\% UPA. LNG-only offers in our judgement were clinically appropriate in $62.5 \%$ cases of such offers.

\section{Key message points}

- By enabling choice, the increased use of FSRH guidelines enhances emergency contraception provision.

- When offered a choice, not all women will choose ulipristal acetate over levonorgestrel.

Conclusions Comparing the second period with the first, more women were offered all three methods, the use of LNG fell $(93.0 \%$ to $76.0 \%)$ and that of UPA increased (3.0\% to $18.7 \%$ ). Women were encouraged to exercise choice. However, increasing choice in our service did not lead to a wholesale change from LNG to UPA.

\section{INTRODUCTION}

Ulipristal acetate (UPA, ellaOne ${ }^{\circledR}$ ) has been available for oral emergency contraception (EC) in the UK since October 2009. Until that time, levonorgestrel (LNG) was the only available oral preparation. The third available, and most effective, mode of EC is a copper-bearing intrauterine contraceptive device (Cu-IUD). ${ }^{1}$ UPA has advantages over LNG in that first, it is active over a longer timescale, being licensed up to 120 hours as opposed to 72 hours after the pregnancy risk. Second, it works closer to the peak of the leuteinising hormone surge, which means that at the time of the menstrual cycle with highest risk of pregnancy ${ }^{2}$ it is more likely to inhibit or delay ovulation than LNG. 
In two randomised, non-inferiority trials appropriately powered to compare equivalence of UPA with LNG, Creinin et al. ${ }^{3}$ and Glasier et al. ${ }^{4}$ showed no statistical superiority in the efficacy of either agent, although there was a suggestion that UPA might have shown greater efficacy. However, Glasier et al. ${ }^{4}$ demonstrated that when combining the data of these two studies in a meta-analysis, UPA did show greater statistical superiority. There has been to date been no study specifically designed to demonstrate UPA's superiority over LNG. The disadvantages of UPA are greater cost (British National Formulary March 2012: Levonelle $^{\circledR}$ 1500: $£ 5.20, € 6.45$, US $\$ 8.36$; ellaOne ${ }^{\circledR}$ $£ 16.95$, $€ 21.02$, US\$27.26) and the possible interaction with progestogen, which has led to the current recommendation for a longer period of additional contraception following administration, if 'quick starting' hormonal contraception after its use. ${ }^{5}$ The Summary of Product Characteristics recommends that UPA cannot be used with concurrent administration of either enzyme inducers or drugs that increase gastric $\mathrm{pH}$ (such as proton pump inhibitors). Nor can it be used more than once in a menstrual cycle or if there has been an episode of unprotected sexual intercourse (UPSI) outside of the treatment window of 120 hours. $^{6}$

In 2011, the UK Faculty of Sexual \& Reproductive Healthcare (FSRH) issued revised clinical guidance on EC. The first recommendation is that the health care professional should discuss individual needs for EC and inform women of the different methods with regard to efficacy, adverse effects interactions, medical eligibility and the resulting need for additional contraceptive precautions. ${ }^{5}$

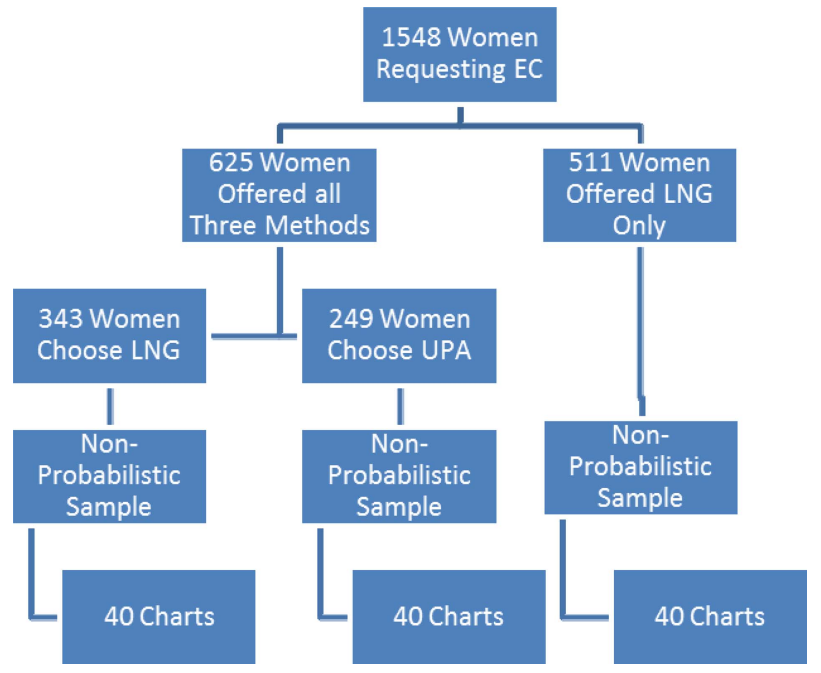

Figure 1 Breakdown of emergency contraception requests in the second 3-month period to demonstrate how the three samples of charts were obtained for examination. EC, emergency contraception; LNG, levonorgestrel; UPA, ulipristal acetate.

\section{EC at Liverpool and Knowsley SRH services}

The Liverpool and Knowsley community-based, sexual and reproductive health care (SRH) services are based at several sites throughout the area, and serve a mixed population of around 600000 . Patients include women from all National Statistics Socio-economic classes, ${ }^{7}$ the unemployed and those from areas with high deprivation indices. Driven by a system of patient self-triage, the majority of EC delivery across our service is undertaken by 'registered practitioners', namely SRH-trained registered nurses and midwives, some of whom are independent prescribers, but most of whom work to patient group directions (PGDs). The PGDs are written in a way so as to be both safe and legal, but also to afford the registered practitioner a degree of freedom in order to use their judgement and experience. For example, the registered practitioners do not work to clinical algorithms. A registered medical specialist in SRH is available for advice during every clinic session.

The long-standing policy is that all eligible women are offered an emergency Cu-IUD (as the most effective method of EC) and can be seen for a fitting within the necessary timeframe. If unable to have immediate $\mathrm{Cu}$-IUD insertion, a clear pathway exists for patient referral for this technique within an appropriate time. In 2010, UPA became available in the service but the recommendation initially was to offer it only to women presenting between 72 to 120 hours after pregnancy risk. In February 2012, our clinical policy was revised to recognise the FSRH guidance that (1) there are issues of relative efficacy of the three available methods of EC and (2) that a woman should be offered all the choices for which she is eligible. Staff were asked to present a balanced choice rather than expressing an immediate preference for UPA. There was a training session on EC for staff in February 2012 at which the revised FSRH guidance was introduced. We have undertaken this service review in order to review how changes in EC delivery and patient choice changed following the introduction of the new guidelines. We were particularly keen to see whether women expressed choice in favour of UPA or the Cu-IUD and how many expressed a preference for LNG.

\section{METHODS}

The larger part of the study was a retrospective chart review of requests for EC undertaken over a period of six complete calendar months: October 2011December 2012 (before the introduction of revised service guidelines) and March-May 2012 (following introduction of the revised guidelines). All episodes of EC were studied, using our Excelicare ${ }^{\circledR}$ system of computerised patient documentation. From this we extracted data on the type of clinician attending the patient, the discussion between the clinician and the patient, the methods of EC offered, and the woman's decision regarding both the method of EC 
administered and future contraceptive provision. We studied four questions: (1) how the actual use of EC changed over time, (2) which methods were offered to the woman and how this had changed, (3) which method was chosen by women who were offered all three options and (4) how many women were offered only LNG and why.

In the smaller part of the study, three nonprobabilistic purposeful samples (40 charts in each sample) of individual practitioners were examined to study patient choice more closely. That is, in the second 3-month period, of the women who were offered all three methods, 40 charts were examined of those who chose UPA and 40 of those who chose LNG. Then 40 charts were similarly chosen to examine whether the offer of LNG as the only agent was appropriate (Figure 1). These charts were chosen as a purposive sample to reflect EC episodes undertaken by a representative spread of staff members in terms of staff role and experience.

\section{RESULTS}

During the two study periods there were between 430 and 535 EC episodes per month (Table 1), giving a 6 -month total of 2989 . The majority of consultations $(2743 ; 92 \%)$ were undertaken by registered practitioners, the rest $(246 ; 8 \%)$ by doctors. The percentage of issuing episodes for UPA rose between the two study periods from $3.0 \%$ to $18.7 \%$, and the percentage of issuing episodes for LNG decreased from $93.0 \%$ to $76.0 \%$ (Table 1). The fitting of a Cu-IUD remained at a rate between $4.0 \%$ and $5.0 \%$. [NB. In 2010/2011, the national rate of emergency Cu-IUD fitting in National Health Service community contraception clinics was $4.0 \% .^{8}$ ]

Table 1 Emergency contraception issued in Liverpool and Knowsley Sexual Heath Service prior to and following the introduction of the revised FSRH guidelines

\begin{tabular}{|c|c|c|}
\hline \multirow[b]{2}{*}{ EC issued } & \multicolumn{2}{|l|}{ 3-month totals* } \\
\hline & $\begin{array}{l}\text { October-December } 2011 \\
\text { [n (\%)] }\end{array}$ & $\begin{array}{l}\text { March-May } 2012 \\
{[n(\%)]}\end{array}$ \\
\hline $\begin{array}{l}\text { Number of women } \\
\text { issued EC }\end{array}$ & 1441 & 1548 \\
\hline \multicolumn{3}{|l|}{$\mathrm{EC}$ issued by } \\
\hline $\begin{array}{l}\text { Registered } \\
\text { practitioner }\end{array}$ & 1321 & 1422 \\
\hline Doctor & 120 & 126 \\
\hline \multicolumn{3}{|l|}{ Type of EC given } \\
\hline LNG & $1339(93.0)$ & $1177(76.0)$ \\
\hline UPA & $43 \quad(3.0)$ & $289(18.7)$ \\
\hline Cu-IUD & $59 \quad(4.0)$ & $82 \quad(5.3)$ \\
\hline \multicolumn{3}{|c|}{$\begin{array}{l}\text { *The percentage figures in parentheses refer to the proportion of each } \\
\text { period's EC episodes. } \\
\text { Cu-IUD, copper-bearing intrauterine contraceptive device; EC, emergency } \\
\text { contraception; FSRH, Faculty of Sexual \& Reproductive Healthcare; LNG, } \\
\text { levonorgestrel; UPA, ulipristal acetate. }\end{array}$} \\
\hline
\end{tabular}

Table 2 Method(s) of emergency contraception offered by Liverpool and Knowsley Sexual Health Service prior to and following the introduction of the FSRH revised guidelines

\begin{tabular}{lll}
\hline & \multicolumn{2}{l}{ 3-month totals* } \\
\cline { 2 - 3 } $\begin{array}{l}\text { EC method(s) } \\
\text { offered }\end{array}$ & $\begin{array}{l}\text { October-December } 2011 \\
{[\boldsymbol{n}(\%)]}\end{array}$ & $\begin{array}{l}\text { March-April } 2012 \\
{[\boldsymbol{n}(\%)]}\end{array}$ \\
\hline $\begin{array}{l}\text { LNG, UPA and } \\
\text { CU-IUD }\end{array}$ & $68(4.7)$ & $625(40.4)$ \\
LNG and Cu-IUD & $872(60.5)$ & $323(20.9)$ \\
LNG & $453(31.4)$ & $511(33.0)$ \\
UPA and Cu-IUD & $16(1.1)$ & $27(1.7)$ \\
CU-IUD & $23(1.6)$ & $30(1.9)$ \\
UPA & $7(0.5)$ & $4(0.3)$ \\
LNG and UPA & $2(0.1)$ & $28(1.8)$ \\
\hline
\end{tabular}

${ }^{*}$ The percentage figures in parentheses refer to the percentage of all EC offered during the 3-month period.

CU-IUD, copper-bearing intrauterine contraceptive device; EC, emergency contraception; FSRH, Faculty of Sexual \& Reproductive Healthcare; LNG,

levonorgestrel; UPA, ulipristal acetate.

Table 2 shows the method of EC offered in the first period compared with the 3 months following the issue of updated FSRH guidance. There is a clear increase in the number of episodes in which all three methods were offered, a corresponding decrease in the number of offers of LNG/Cu-IUD methods, and a very slight increase in the offer of LNG only. The figures concerning the other categories are shown in Table 2 but they are too small to be used to draw any conclusions.

Table 3 shows the method chosen by the 625 women who were offered all three methods in the 3 -month period following our new guidance. Of these women, 343 (55\%) chose LNG, 249 (40\%) UPA and $33(5 \%)$ a Cu-IUD.

Table 4 shows data on the future contraceptive choice of 80 women who were offered all three EC methods, 40 of whom chose UPA and 40 who chose LNG. Of those women who were 'quick started' or were already using hormonal contraception, 17 received UPA and 27 LNG; as regards using condoms, the figures for the two groups were 17 and 10, respectively. Equal, but small numbers (two in each

Table 3 Method chosen by women who were offered all three methods of emergency contraception following the introduction of the revised FSRH guidelines

\begin{tabular}{llccl}
\hline $\mathbf{2 0 1 2}$ & LNG $[\boldsymbol{n}(\%)]^{*}$ & UPA $[\boldsymbol{n}(\%)]$ & Cu-IUD $[\boldsymbol{n}(\%)]$ & Total $(\boldsymbol{n})$ \\
\hline March & $107(54.9)$ & $79(40.5)$ & $9(4.6)$ & 195 \\
April & $109(55.3)$ & $79(40.1)$ & $9(4.6)$ & 197 \\
May & $127(54.5)$ & $91(39.1)$ & $15(6.4)$ & 233 \\
Total & $343(54.9)$ & $249(39.8)$ & $33(5.3)$ & 625 \\
\hline
\end{tabular}

${ }^{*}$ The percentage figures in parentheses refer to the percentage of each month's EC episodes of women choosing one of the three methods. CU-IUD, copper-bearing intrauterine contraceptive device; EC, emergency contraception; FSRH, Faculty of Sexual \& Reproductive Healthcare; LNG, levonorgestrel; UPA, ulipristal acetate. 
Table 4 Future contraception in the 80 women offered all three methods but choosing oral emergency contraception

\begin{tabular}{|c|c|c|}
\hline \multirow[b]{2}{*}{ Ongoing contraception } & \multicolumn{2}{|c|}{ Method chosen* } \\
\hline & UPA $[n(\%)]$ & LNG $[n(\%)]$ \\
\hline $\begin{array}{l}\text { 'Quick starting' or continuing } \\
\text { hormonal contraception }\end{array}$ & $17(42.5)$ & $27(67.5)$ \\
\hline Using condoms & $17(42.5)$ & $10(25.0)$ \\
\hline $\begin{array}{l}\text { Declined ongoing } \\
\text { contraception (not in a } \\
\text { relationship) }\end{array}$ & $2(5.0)$ & $2(5.0)$ \\
\hline $\begin{array}{l}\text { Starting hormonal method } \\
\text { following next period }\end{array}$ & $4(10.0)$ & $1(2.5)$ \\
\hline
\end{tabular}

group) declined any ongoing method. Of those who were starting hormonal contraception with the next period, four chose UPA and one LNG. In total, of the group of women who chose LNG, five were documented as wanting combined hormonal contraception to be effective as soon as possible (they were 'quick starting'), and four had used LNG previously without any problems and expressed a preference for it. These four were all planning to use condoms for future contraception.

There was a variety of reasons why women were only offered LNG, including those listed below.

1 No clinical need for EC, but the woman was insistent (e.g. recently commenced hormonal contraception at the start of her period with no missed pills and less than two missed combined oral contraceptive pills).

2 UPSI in a 'negligible risk' time of her cycle, up to Day 3 of a 28-day menstrual cycle.

3 Multiple episodes of risk during the current cycle more than 120 hours before the request, when UPA is contraindicated and where there was a risk of implantation when an $\mathrm{Cu}-\mathrm{IUD}$ is not an option. Examining this sample (Table 5) our interpretations of the clinical circumstances were that $16 / 40$ women were not eligible for any method other than LNG, and three were not at risk of pregnancy. In six women the documentation was not particularly clear but it seemed probable that the clinician felt the pregnancy risk to be low based upon the time in the cycle that UPSI occurred such that there was no to low risk of pregnancy, and it seems 15 women might have been offered other options.

\section{DISCUSSION}

Following the introduction of guidelines incorporating revised FSRH guidance there was a marked increase in the number of women offered all three EC methods and a corresponding decrease in the number of offers of LNG/Cu-IUD only. There were insufficient numbers to judge the degree of any trend in some of the other categories of method offered, and the veracity of our findings is reliant upon accurate clinical record-keeping. It is possible that more choices were offered than recorded if they were very quickly dismissed by the woman so that they were not discussed in any detail. The number of women offered LNG only showed a marginal increase.

It could be asked why it was that all three methods were not offered for every episode of EC? We believe that it is one of the strengths of our service that our registered practitioners have the opportunity to use their knowledge and experience to tailor the consultation to each woman's individual circumstances. It might not in practice be appropriate for every woman to be offered every method for every episode of EC as the Faculty acknowledges. We have discussed why this might be, for example, some women may not be at risk, and some are not eligible for every available method. Although it is thought to have greater efficacy, our practitioners do not universally adopt UPA as the main agent of oral EC, yet they are seen to be offering the woman appropriate choice. There is still

Table 5 Background data of the 40 women in the second study period who were offered only levonorgestrel

\begin{tabular}{|c|c|}
\hline Reason & Women $(n)$ \\
\hline \multicolumn{2}{|l|}{ Multiple episodes UPSI } \\
\hline $\begin{array}{l}\text { First episode more than } 120 \text { hours ago and not } \\
\text { eligible for Cu-IUD (not within permitted time } \\
\text { parameters) }\end{array}$ & 15 \\
\hline \multicolumn{2}{|l|}{ Single risk in current menstrual cycle } \\
\hline$\geq$ Day 3 & 1 \\
\hline$\leq$ Day $4-19$ & 9 \\
\hline Day 20+ & $\begin{array}{l}6 \text { (Day } 20-22, n=3 \text {; } \\
\text { Day } 25-28, n=3 \text { ) }\end{array}$ \\
\hline \multicolumn{2}{|l|}{$\begin{array}{l}\text { On first packet of oral contraception (started } \\
\text { before Day } 2 \text { of cycle) - no missed pills }\end{array}$} \\
\hline SI without condom. Adamant needed EC & 2 \\
\hline Others & 7 \\
\hline
\end{tabular}

Last DMPA injection 6 months earlier.

Amenorrhoea. Using condoms. Split condom

$>72$ hours and $<92$ hours earlier. No other risks

Last DMPA injection 6 months earlier.

Amenorrhoea. UPSI $<24$ hours ago. No mention

of previous $\mathrm{SI}$

LMP 3 weeks earlier. Missed four COC pills. UPSI

$<24$ hours earlier

$14+2$ weeks since last DMPA injection. UPSI

33 hours earlier

LMP 3 weeks ago. Vomited last few days, no missed pills. No mention of when vomited or had SI

51-year-old. IUS fitted 3 years previously. Amenorrhoea. Threads not visible. Last SI

60 hours earlier

53-year-old. LMP 4 months earlier. Requesting Cu-IUD removal. SI 1 day earlier

COC, combined oral contraceptive; CU-IUD, copper-bearing intrauterine contraceptive device; DMPA, depot medroxyprogesterone acetate;

EC, emergency contraception; IUS, intrauterine system; LMP, last menstrual period; SI, sexual intercourse; UPA, ulipristal acetate; UPSI, unprotected sexual intercourse. 
clearly a place for LNG; and although two-thirds of the women were offered a Cu-IUD, few were happy to accept this method.

Review of our clinical practice shows that although women might be informed of the superior efficacy of $\mathrm{Cu}-\mathrm{IUD}$ and UPA, some women are familiar with LNG and prefer it (Table 3). As mentioned previously, patients have access to $\mathrm{Cu}-\mathrm{IUD}$ insertion, but this may not be undertaken immediately, which might have influenced the figures. There is also an issue around the length of time during which extra contraceptive precautions are necessary with UPA. Fortunately our clinicians' documentation was comprehensive enough to be able to glean these data. Some services have been concerned about the greater cost of UPA compared with LNG. Thomas et al. have calculated that the incremental cost-effectiveness ratio to prevent one additional unintended pregnancy with UPA ranges from $£ 183$ to $£ 500$ depending on the time administered from the risk episode. ${ }^{9}$ However, their study was based upon clinical trials that did not include women who had missed pills and so the figures should be interpreted with a degree of caution.

The sample of 80 charts chosen to examine patient choice more closely was not a random sample, nor was the sample of 40 charts chosen to study the offer of only LNG. They were non-probabilistic, purposeful samples chosen to reflect the practices of a comprehensive range of roles and experience among staff members. It should be pointed out that ours is a large service and not all staff members were able to attend the initial launch of the revised guidelines. These factors are a potential source for bias in our findings. With time, women's greater familiarity with UPA may influence patient choice. There is a suggestion that body mass index influences pregnancy risk following EC, but the FSRH has called for more evidence before a recommendation is made regarding the use of LNG or UPA. ${ }^{5}$ There was no evidence that body weight influenced the thought processes of our clinicians.

It is possible that the concern many UK practitioners have that the more costly UPA will become the method of choice may be unfounded. The Cu-IUD should always be considered as an option, where possible, but it seems clear that women generally are not choosing this method of EC. UPA should be available in all services as it is the only licensed oral preparation for use between 72 and 120 hours; consequently all staff must be able to discuss its use with women. However, we should bear in mind that the Cu-IUD is always the most effective and cost-effective EC method. Although there is a reduced risk of pregnancy after Day 20 of a 28-day cycle there is still risk. Also a woman can have an inaccurate perception of the actual date of her last menstrual period (LMP). ${ }^{10}$ Stirling and Glasier studied 94 women requesting $\mathrm{EC}$ and compared the reported date of the LMP against urinary pregnanediol levels in 64 women to assess whether they had ovulated before they used EC. Twenty-one women had pregnanediol levels inconsistent with their cycle day. The usage of UPA could depend upon the clinician's perception of this being an issue. It would be interesting to study the situation in 12 months' time to measure the effects of greater staff familiarity with the issue, and greater patient knowledge about UPA.

\section{CONCLUSIONS}

We have found it possible, within a predominantly nurse-delivered EC service, to follow the recommendations of the FSRH to consider and, if possible, offer all three currently available EC methods. Generally practitioners appear to be using their knowledge and experience to tailor the advice they give women and are mainly providing EC appropriately based upon an individual woman's clinical need. There still remains a place for the use of LNG: in some cases this was seen to be the most appropriate agent for the woman concerned. The purposive sample highlighted that in other cases women were favouring LNG over UPA and $\mathrm{Cu}-\mathrm{IUD}$. Some women are keen to use LNG as it lessens the period of time during which additional contraceptive precautions are necessary. In other cases, the woman has used LNG previously and is happy to use it again, and some women cannot be offered any other method because of the risk of a preimplanted pregnancy: some women were offered LNG alone because they were judged not to be at risk of pregnancy.

We endorse the FSRH recommendation that all clinicians should be trained to offer all appropriate methods of EC, and to discuss each method and each individual woman's needs. Our study has demonstrated that increasing choice does not lead to wholesale change from LNG to UPA, and health commissioners should not restrict EC choice due to fear of increased service costs.

Acknowledgements The author wishes to thank Dr Anne Webb for her advice in the preparation of this paper and Paul Dudley for retrieving the data.

Competing interests The author is a current member of the FSRH Clinical Effectiveness Committee.

Provenance and peer review Not commissioned; externally peer reviewed.

\section{REFERENCES}

1 Cleland K, Zhu H, Goldstuck N, et al. The efficacy of intrauterine devices for emergency contraception: a systematic review of 35 years of experience. Hum Reprod 2012;27:1994-2000.

2 Gemzell-Danielsson K, Meng CX. Emergency contraception: potential role of ulipristal acetate. Int J Womens Health 2010;2:53-61.

3 Creinin MD, Schlaff W, Archer DF, et al. Progesterone receptor modulator for emergency contraception: a randomised controlled trial. Obstet Gynecol 2006;108:1089-1097. 
4 Glasier AF, Cameron ST, Logan SJS, et al. Ulipristal acetate versus levonogestrel for emergency contraception: a randomised non-inferiority trial and meta-analysis. Lancet 2010;375:555-562.

5 Faculty of Sexual \& Reproductive Healthcare Clinical Effectiveness Unit. Emergency Contraception. (August 2011, updated January 2012). http://www.fsrh.org/pdfs/ CEUguidanceEmergencyContraception11.pdf [accessed 12 January 2013].

6 HRA Pharma UK Ltd. ellaOne: Summary of Product Characteristics (SPC). 2011. http://www.medicines.org.uk/emc [accessed 12 August 2012].

7 The National Statistics Socio-economic Classification. http://www.ons.gov.uk/ons/guide-method/classifications/ current-standard-classifications/soc2010/ soc2010-volume-3-ns-sec-rebased-on-soc2010user-manual/index.html\#6 [accessed 12 January 2013].

8 The NHS Information Centre, Lifestyles Statistics. NHS Contraceptive Services: England, 2010/11 Community Contraceptives Clinics. 1 December 2011. https://catalogue.ic.nhs. uk/publications/public-health/contraception/nhs-cont-serv-commcont-clin-eng-2010-2011/nhs-cont-serv-comm-cont-clin-eng-10-11rep.pdf [accessed 12 August 2012].

9 Thomas CM, Schmid R, Cameron S. Is it worth paying more for emergency hormonal contraception? The cost-effectiveness of ulipristal acetate versus levonorgestrel $1.5 \mathrm{mg}$. J Fam Plann Reprod Health Care 2010;36:197-201.

10 Stirling A, Glasier A. Estimating the efficacy of emergency contraception - how reliable are the data? Contraception 2001;66:19-22. 